\title{
Clinical Application of Primary Suture Following Three-Port Laparoscopic Common Bile Duct Exploration: A Report of 176 Cases
}

\author{
Shengze Li1, Huihua Cai ${ }^{2}$, Donglin Sun ${ }^{2}$, Xuemin Chen ${ }^{2}$, Shengyong Liu ${ }^{2}$, Xinquan $\mathrm{Wu}^{2}$, \\ Yong An ${ }^{2}$, Jing Chen ${ }^{2}$, Chun Yang², Yaping Sun ${ }^{2}$, Xiaoyan $\mathrm{Lu}^{2}$ \\ ${ }^{1}$ Department of General Surgery, The Third People's Hospital of Jiangyin, Wuxi, China \\ ${ }^{2}$ Department of Hepatobiliary Surgery, The First People's Hospital of Changzhou, The 3th Hospital Affiliated to \\ Soochow University, Suzhou, China \\ Email: ${ }^{*}$ chh1168@163.com
}

Received 12 December 2014; accepted 25 December 2014; published 14 January 2015

Copyright (C) 2015 by authors and Scientific Research Publishing Inc.

This work is licensed under the Creative Commons Attribution International License (CC BY). http://creativecommons.org/licenses/by/4.0/

\section{(c) (i) Open Access}

\begin{abstract}
Objective: To investigate the feasibility, safety and the clinical value of primary suture following 3-port laparoscopic common bile duct exploration (LCBDE). Methods: From January 2012 to September 2014, 176 patients suffered from choledocholithiasis were treated with primary suture following 3-port LCBDE and the clinical data were retrospectively analyzed. Results: All cases were operated successfully and none was converted to open surgery. The duration of operation was $92.2 \pm 18.8 \mathrm{~min}$ and the length of postoperative hospital stay was $4.4 \pm 3.7 \mathrm{~d}$. Postoperative bile leakage occurred in 2 cases and these patients recovered by simple drainage for 3 to 7 days without re-operation. All patients recovered smoothly without any serious complications. Conclusions: Primary suture following 3-port LCBDE is safe, effective and mini-invasive, which is worthy of further clinical application.
\end{abstract}

\section{Keywords}

Laparoscopy, Common Bile Duct Exploration, Primary Suture, Three-Port

\section{Introduction}

Laparoscopic cholecystectomy (LC) has become the standard method for cholecystectomy, but laparoscopic surgery is not the gold standard for common bile duct stones. With the development of techniques and improvement of instruments, 4-port laparoscopic common bile duct exploration (LCBDE) has been used to treat ${ }^{*}$ Corresponding author. 
choledocholithiasis for many years in clinical practice [1]-[4]. The purpose of this study was to investigate the feasibility, safety and the clinical value of primary suture following 3-port laparoscopic common bile duct exploration (LCBDE).

\section{Methods}

\subsection{General Data}

From January 2012 to September 2014, of the 176 patients with choledocholithiasis who responded to the survey, 67 (38.1\%) were male and 109 (61.9\%) female, with an average age of 64 years (range, 22 - 91 years). Preoperative common bile duct stones and/or dilation were diagnosed by B-type ultrasound, CT, magnetic resonance cholangiopancreatography (MRCP) or endoscopic resonance cholangiopancreatography (ERCP). And the mean diameter of common bile duct was $1.2 \mathrm{~cm}$ (range, 0.8 - $2.3 \mathrm{~cm}$ ) (Table 1).

\subsection{Surgical Protocols}

All procedures were performed by one single surgical team. After general endotracheal anesthesia was administered, the operation was carried out using the three-port technique: the first port was a $10-\mathrm{mm}$ supraumbilical camera port with $12 \mathrm{mmHg} \mathrm{CO}$ insufflation and the other two ports (10-mm subxiphisternum and 5-mm right upper quadrant) were inserted under direct $30^{\circ}$ video-laparoscope (Storz, German) vision.

The operation with the patient positioned supine was started with dissection of Calot's triangle and clipping and division of the cystic artery. Routine trans-cystic intro-operative cholangiography (IOC) was performed in all patients with 30\% compound Diatrzoatc Meglumlne to help us confirm the anatomy of bile duct and the number/location of stones in common bile duct (CBD) (Figure 1).

Table 1. Clinical details of patients with choledocholithiasis.

\begin{tabular}{cc}
\hline & Cases (\%) \\
\hline Total no. & 176 \\
Age range (yr) & $22-91$ \\
Male patients & $67(38.1 \%)$ \\
Female patients & $109(61.9 \%)$ \\
Abnormal LFT & $104(59.1 \%)$ \\
Jaundice & $48(27.3 \%)$ \\
Acute cholecystitis & $57(32.4 \%)$ \\
Pancreatitis & $18(10.2 \%)$ \\
Preoperative ERCP + EST & $15(8.5 \%)$ \\
\hline
\end{tabular}

a: Liver function test.

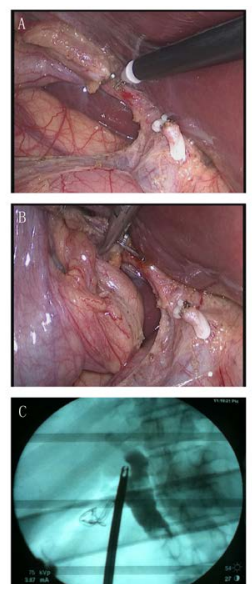

Figure 1. (A): The Calot's triangle was dissected and anterior wall of cystic duct was pre-coagulated to prevent bleeding; (BC): Trans-cystic intro-operative cholangiography (IOC) was performed with 30\% compound Diatrzoatc Meglumlne. 
A laparoscopic cholecystectomy was performed in the standard anterograde fashion. A carbasus was inserted into foramen of Winslow to keep from stones sliding into the lesser omental sac. In cases of cystic duct was dilated sufficiently to allow CBD exploration, a longitudinal incision was made to CBD and the choledochoscope could get through. Sometimes washing of CBD by the suction with a soft pipe was another supplementary way to remove the stones. Once stones were retrieved, the incision was sutured and the cystic duct was ligated with a Hem-o-lok (Tyco, USA). When the CBD was approached directly, a longitudinal supraduodenal CBD wall was pre-coagulated to prevent bleeding and then a incision according to the stone was made using a microscissors. CBD stones were entirely retrieved using a wire basket in all patients and the basket should be passed through distal CBD into duodenum to prevent the retained stones incarcerated in oddi sphincter muscle. No evidence was found of intra-/extra-hepatic bile duct stones or obstruction (Figure 2) and the incision of CBD was closed with 4-0 vicryl sutures (Johnson \& Johnson, USA). To avoid short-/long-term stenosis of CBD, the suture of both CBD margins can not be too much. The fixed location of trocar and angle of suture needle, especially three-port LCBDE without help of assistant made the sutures more difficult to do. It was of great importance to exposure hepatic hilum or cystic duct with left hand and the incision of CBD was drawn by suture needle one by one for purpose of successful suture. A cavernous suction drainage was placed beside the incision of CBD in all patients after removal of gallbladder and stones (Figure 3).
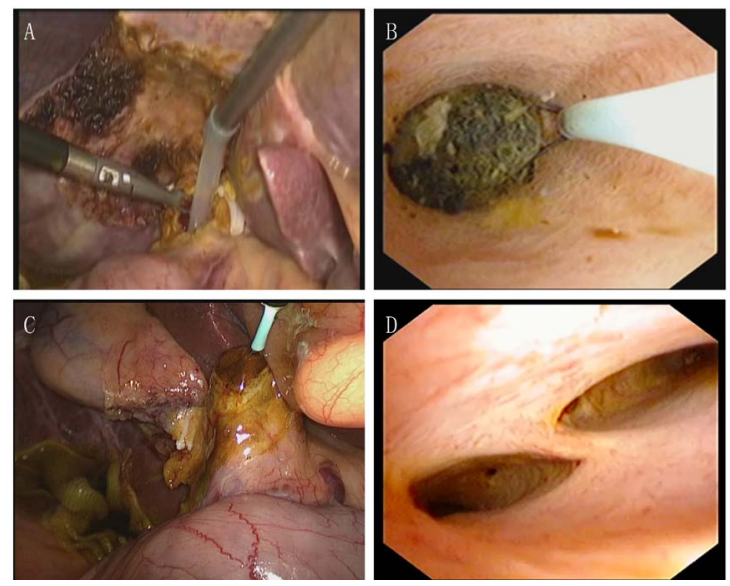

Figure 2. (A): Washing of CBD by the suction with a soft pipe was an efficient way to remove the stones; (BC): CBD stone was retrieved using a wire basket; (D): No evidence was found of intra-/extra-hepatic bile duct stones or obstruction.
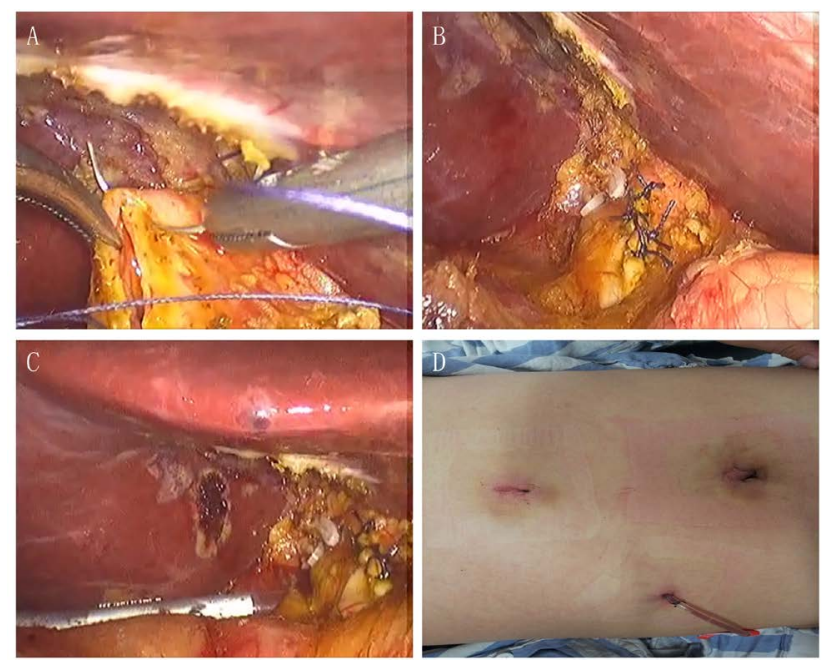

Figure 3. (AB): The incision of CBD was closed with 4-0 vicryl sutures; (C): A cavernous suction drainage was placed beside the incision of CBD after removal of gallbladder and stones; (D): The picture of the three incisions and the drainage tube from 5-mm Trocar in right upper quadrant. 


\subsection{Follow-Up}

All patients were routinely followed up 12 months after discharge. B-ultrasonic examination and LFTs were used in every patients.

\section{Results}

All cases were operated successfully without converting to open surgery. The rate of intra-operative CBD stones removel was $100 \%$. The duration of operation was $92.2 \pm 18.8 \mathrm{~min}$ and the mean time of choledochoscopy was 9.4 (4 - 19) min. The patients were allowed to drink water $12 \mathrm{~h}$ after operation and the length of postoperative hospital stay was $4.4 \pm 3.7 \mathrm{~d}$. The drainage was removed $3 \mathrm{~d}$ postoperatively only if bile leakage happened. 2 cases occurred bile leakage and recovered by simple drainage for another 3 to 7 days without re-operation. The median follow-up was 12 months and all patients recovered smoothly without any serious complications.

\section{Discussion}

The presence of common bile duct stones (CBDS) significantly increases the morbidity, mortality, and cost of patients with gallstones. The potential complications of choledocholithiasis, cholangitis, and pancreatitis could be life-threatening [5] [6].

Surgery is still the main method to treat choledocholithiasis associated with cholelithiasis. Conventional open cholecystectomy and CBDE is confirmed as a safe modus operandi, but it has more trauma and longer hospital stay compared with laparoscopic surgery. Endoscopic sphincterotomy (ES) was an approach and it was first described in 1974. Today, ES for choledocholithiasis remains the most difficult and dangerous procedure routinely performed by endoscopists. The application of ES to CBD stones was advocated for patients with cholangitis, acute biliary pancreatitis, and for elderly high-risk patients [7] [8]. It is reported that the ductal stone clearance rate is $89 \%-91.7 \%$ and complication rate is $8.8 \%-12.3 \%$ [9] [10].

Although intra-operative ES was performed by experienced gastroenterologists, it still resulted in procedurerelated complications that could be life-threatening [11]-[14]. Most LCBDEs in this series were performed via the cystic duct because of the stone characteristics and ductal anatomy. Trans-cystic route was another choice for Laparoscopic CBDE, which was limited by anatomy of cystic duct, the number/size and location of CBD stone, shortcoming of choledochoscopy and so on. All of above resulted in the low success rate and more complications [15].

On the contrary, LCBDE combined with lithotomy through cholangioscopy has many advantages as follows: 1) patients suffered from common bile duct stones secondary to gallbladder stones can be treated by one surgery (LC + LCBDE) successfully; 2) residuary stones in intra-/extra-hepatic bile duct can be removed via T-tube sinus tract without another hospitalization; 3) postoperative cholangiography is facilitated through T-tube; 4) less trauma, faster postoperative recovery with few complications. LCBDE can meet with the same efficacy as conventional open surgery and it has become the main method to treat choledocholith associated with cholecystolithiasis. Intraoperative utilization of cholangioscopy is an effective approach to keep from residual stones of intra-/extra-hepatic bile duct. In principle, the CBD stones should be identified and removed during the surgery, instead of post-operation.

Traditionally T-tube drainage was followed by common bile duct exploration whether open surgery or laparoscopic surgery. With the development of laparoscopic instruments and stitches, primary closure was applied to clinic practice successfully [16]. In comparison to primary suture, the postoperative rehabilitation of patients with T-tube drainage was slower because of water-electrolyte disorder and poor digestion. Meanwhile, patients with T-tube and extubation might meet with a series of complications such as biliary fistula, bile peritonitis, intestinal fistula, biliary tract infection, infection around T-tube, slippage/breakage of T-tube, inflammatory hyperplasia/stenosis of CBD, etc. [3] [17]-[19]. Currently, most LCBDE is performed through 4-port method. We try to put 3-port method into practice based on more than 100 cases' experience of 4-port LCBDE.

In our opinion, the following tips must be keep in mind: 1) make the best use of the use of body position (the first high-pin low with left $15^{\circ}-30^{\circ}$ tilt position) to expose operating field; 2) LC is performed first to reduce the impact of gallbladder; 3 ) the anterior wall of the CBD was pre-coagulated to prevent bleeding and a carbasus was inserted into foramen of Winslow to keep from stones sliding into the lesser omental sac; 4) Choledochoscope is inserted from 12-mm subxiphisternal trocar to keep from damage of choledochoscope and the trocar can 
be selected a longer one if necessary; 5) no residual stones are confirmed and CBD is closed with 4-0 vicryl sutures; 6) suture of both CBD margins can not be too much to avoid postoperative stenosis; 7) exposure of hepatic hilum or cystic duct with left hand and the incision of CBD is drawn by suture needle one by one for purpose of successful suture; 8 ) a cavernous suction drainage must be placed beside the incision of CBD routinely.

In our study, all patients were performed successfully. Two cases occurred postoperative bile leakage with 10 $30 \mathrm{ml}$ per day. Anisodamine (654-2) was used to relieve the sphincter of Oddi spasm and patients recovered with 3 - $7 \mathrm{~d}$ drainage without re-operation. Pinhole biliary leakage is in consideration.

We believe that primary suture following LCBDE is not suitable for all patients suffered from CBD stones. The indications are as follows: 1) CBD stones secondary to gallbladder stones without intrahepatic bile duct stones; 2) no residual stones were confirmed in intra-/extra-hepatic bile duct by intraoperative choledochoscope; 3 ) the function of oddi sphincter was well and no evident edema or neoplasma occurred in the distal CBD; 4) the diameter of CBD was more than $8 \mathrm{~mm}$ in order to avoid postoperative bile duct stricture [20] [21]. The followings are considered as contraindication for primary closure: 1) extrahepatic bile duct multiple stones were not removed completely; 2) the diameter of CBD was less than $8 \mathrm{~mm}$; 3) acute suppurative cholangitis with CBD wall severe edema; 4) stenosis or obstruction existed in the distal CBD; 5) server Mirizzi syndrome [22].

As a selective surgical approach, primary suture following three-port laparoscopic common bile duct exploration can be applied to the patients suffered from CBD stones and the indications and contraindications should be strictly followed.

\section{Conflict of Interest}

All authors have reviewed the final version of the manuscript and approve it for publication. None of the authors of this manuscript have a financial interest related to this work.

\section{Open Access}

This article is distributed under the terms of the Creative Commons Attribution Noncommercial License which permits any noncommercial use, distribution, and reproduction in any medium, provided the original author(s) and source are credited.

\section{References}

[1] Shively, E.H., Richardson, M., Romines, R., Englund, G. and Watkins, J. (2010) Laparoscopic Common Duct Exploration in 90-Bed Rural Hospital. The American Surgeon, 76, 626-629.

[2] Chander, J., Vindal, A., Lal, P., Gupta, N. and Ramteke, V.K. (2011) Laparoscopic Management of CBD Stones: An Indian Experience. Surgical Endoscopy, 25, 172-181. http://dx.doi.org/10.1007/s00464-010-1152-5

[3] Zhang, W.J., Xu, G.F., Wu, G.Z., Li, J.M., Dong, Z.T. and Mo, X.D. (2009) Laparoscopic Exploration of Common Bile Duct with Primary Closure versus T-Tube Drainage: A Randomized Clinical Trial. Journal of Surgical Research, 157, e1-e5. http://dx.doi.org/10.1016/j.jss.2009.03.012

[4] Tinoco, R., Tinoco, A., El-Kadre, L., Peres, L. and Sueth, D. (2008) Laparoscopic common Bile Duct Exploration. Annals of Surgery, 247, 674-679. http://dx.doi.org/10.1097/SLA.0b013e3181612c85

[5] Zhang, W.Z., Chen, Y.S., Wang, J.W. and Chen, X.R. (2002) Early Diagnosis and Treatment of Severe Acute Cholangitis. World Journal of Gastroenterology, 8, 150-152

[6] Kohut, M., Nowak, A., Nowakowska-Duiawa, E. and Marek, T. (2002) Presence and Density of Common Bile Duct Microlithiasis in Acute Biliary Pancreatitis. World Journal of Gastroenterology, 8, 558-561

[7] Cuschieri, A., Lezoche, E., Morino, M., Croce, E., Lacy, A., Toouli, J., Faggioni, A., Ribeiro, V.M., Jakimowicz, J., Visa, J. and Hanna, G.B. (1999) E.A.E.S. Multicenter Prospective Randomized Trial Comparing Two-Stage vs Single-Stage Management of Patients with Gallstone Disease and Ductal Calculi. Surgical Endoscopy, 13, 952-957. http://dx.doi.org/10.1007/s004649901145

[8] Martin, D.J., Vernon, D.R. and Toouli, J. (2006) Surgical versus Endoscopic Treatment of Bile Duct Stones. Cochrane Database of Systematic Reviews, 19, CD003327.

[9] Gong, J.P., Zhou, Y.B., Han, B.L. and Li, Z.H. (1999) Endoscopic Sphincterotomy in Treatment of Secondary Common Bile Duct Stones. Shijie Huaren Xiaohua Zazhi, 7, 320-322

[10] Wei, Q., Wang, J.-G., Li, L.-B. and Li, J.-D. (2003) Management of Choledocholithiasis: Comparison between Lapa- 
roscopic Common Bile Duct Exploration and Intraoperative Endoscopic Sphincterotomy. World Journal of Gastroenterology, 9, 2856-2858.

[11] He, G.H., Cai, Y., Qian, X.Y., Feng, G.H., Ying, R.C., Xu, Q. and Jia, P.H. (2002) Surgical Management of the Complications after Endoscopic Sphincterotomy. Chinese Journal of General Surgery, 17, 469-470.

[12] Freeman, M.L., DiSario, J.A., Nelson, D.B., Fennerty, M.B., Lee, J.G., Bjorkman, D.J., Overby, C.S., Aas, J., Ryan, M.E., Bochna, G.S., Shaw, M.J., Snady, H.W., Erickson, R.V., Moore, J.P. and Roel, J.P. (2001) Risk Factors for Post-ERCP Pancreatitis: A Prospective, Multicenter Study. Gastrointestinal Endoscopy, 54, 425-434. http://dx.doi.org/10.1067/mge.2001.117550

[13] Vandervoort, J., Soetikno, R.M., Tham, T.C., Wong, R.C., Ferrari Jr., A.P., Montes, H., Roston, A.D., Slivka, A., Lichtenstein, D.R., Ruymann, F.W., Van Dam, J., Hughes, M. and Carr-Locke, D.L. (2002) Risk Factors for Complications after Performance of ERCP. Gastrointestinal Endoscopy, 56, 652-656. http://dx.doi.org/10.1016/S0016-5107(02)70112-0

[14] Masci, E., Toti, G., Mariani, A., Curioni, S., Lomazzi, A., Dinelli, M., Minoli, G., Crosta, C., Comin, U., Fertitta, A., Prada, A., Passoni, G.R. and Testoni, P.A. (2001) Complications of Diagnostic and Therapeutic ERCP: A Prospective Multicenter Study. The American Journal of Gastroenterology, 96, 417-423. http://dx.doi.org/10.1111/j.1572-0241.2001.03594.x

[15] Topal, B., Aerts, R. and Penninckx, F. (2007) Laparoscopic Common Bile Duct Stone Clearance with Flexible Choledochoscopy. Surgical Endoscopy, 21, 2317-2321. http://dx.doi.org/10.1007/s00464-007-9577-1

[16] Jameel, M., Darmas, B. and Baker, A.L. (2008) Trend towards Primary Closure Following Laparoscopic Exploration of the Common Bile Duct. Annals of the Royal College of Surgeons of England, 90, 29-35. http://dx.doi.org/10.1308/003588408X242295

[17] Yamazaki, M., Yasuda, H., Tsukamoto, S., Koide, Y., Yarita, T., Tezuka, T., Takenoue, T., Kosugi, C., Sugimoto, M., Yamamoto, S. and Naka, S. (2006) Primary Closure of the Common Bile Duct in Open Laparotomy for Common Bile Duct Stones. Journal of Hepato-Biliary-Pancreatic Surgery, 13, 398-402. http://dx.doi.org/10.1007/s00534-005-1097-6

[18] Leida, Z., Ping, B., Shuguang, W. and Yu, H. (2008) A Randomized Comparison of Primary Closure and T-Tube Drainage of the Common Bile Duct after Laparoscopic Choledochotomy. Surgical Endoscopy, 22, 1595-1600. http://dx.doi.org/10.1007/s00464-007-9731-9

[19] Zhu, Q.D., Tao, C.L., Zhou, M.T., Yu, Z.P., Shi, H.Q. and Zhang, Q.Y. (2011) Primary Closure versus T-Tube Drainage after Common Bile Duct Exploration for Choledocholithiasis. Langenbeck's Archives of Surgery, 396, 53-62. http://dx.doi.org/10.1007/s00423-010-0660-z

[20] Cai, H.H., Sun, D.L., Sun, Y.M., Bai, J.F., Zhao, H.L. and Miao, Y. (2011) Primary Closure Following Laparoscopic Common Bile Duct Exploration Combined with Intra-Operative Cholangiography and Choledochoscopy. World Journal of Surgery, 36, 164-170. http://dx.doi.org/10.1007/s00268-011-1346-6

[21] Sun, D.L., Zhang, F., Chen, X.M., Jiang, H.Y., Yang, C., Sun, Y.P., Yang, B., Yang, Y., Cai, H.H., Wang, C.Y. and Wu, X.Q. (2012) Clinical Efficacy and Safety of Selective Trans-Cystic Intra-Operative Cholangiography in Primary Suture Following Three-Port Laparoscopic Common Bile Duct Exploration. Chinese Medical Journal, 125, 35093513.

[22] Chowbey, P.K., Sharma, A., Mann, V., Khullar, R., Baijal, M. and Vashistha, A. (2000) The Management of Mirizzi Syndrome in the Laparoscopic era. Surgical Laparoscopy Endoscopy Percutaneous Techniques, 10, 11-14. http://dx.doi.org/10.1097/00129689-200002000-00003 
Scientific Research Publishing (SCIRP) is one of the largest Open Access journal publishers. It is currently publishing more than 200 open access, online, peer-reviewed journals covering a wide range of academic disciplines. SCIRP serves the worldwide academic communities and contributes to the progress and application of science with its publication.

Other selected journals from SCIRP are listed as below. Submit your manuscript to us via either submit@scirp.org or Online Submission Portal.
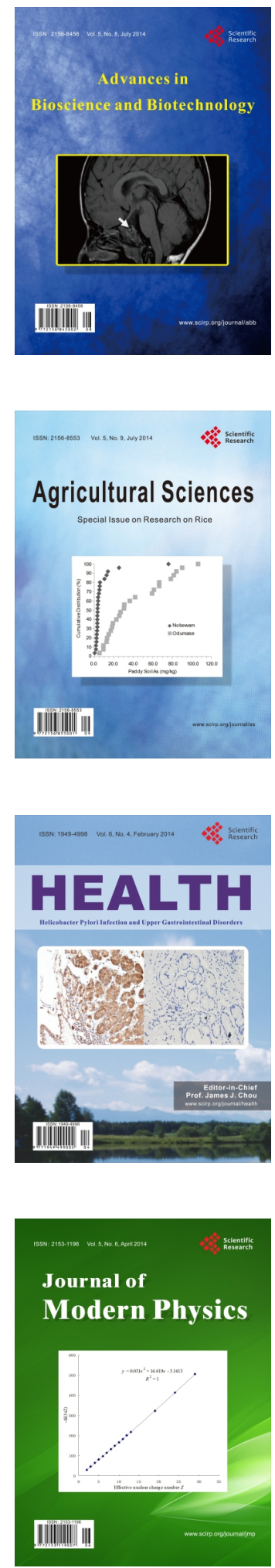
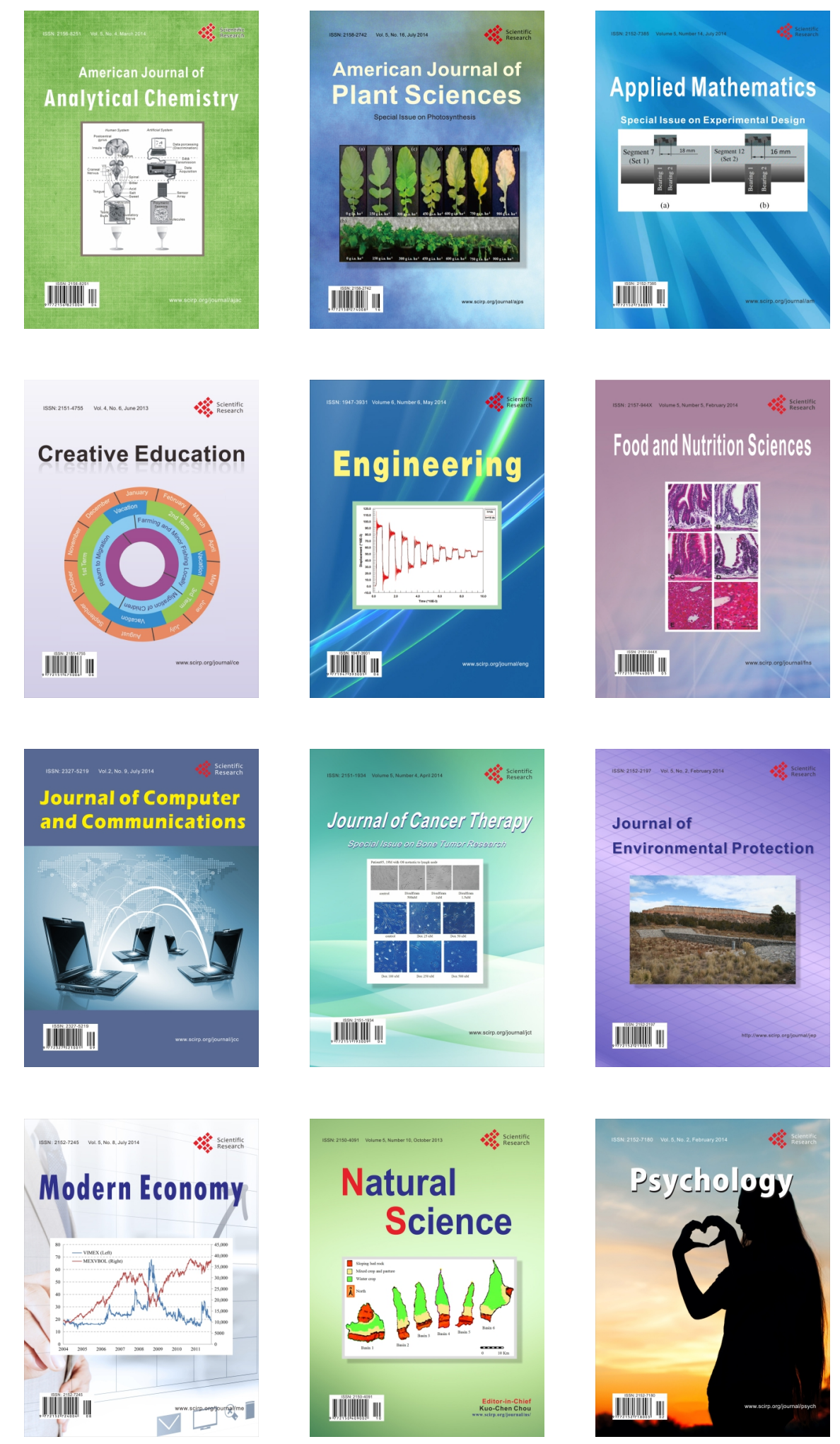